Check for updates

Cite this: RSC Adv., 2018, 8, 37410

\title{
Specific and sensitive imaging of basal cysteine over homocysteine in living cells $\uparrow$
}

\author{
Longxue Nie, Bingpeng Guo, Congcong Gao, Shaowen Zhang, * Jing Jing (D) * \\ and Xiaoling Zhang (D)
}

Biological thiols play important roles in maintaining appropriate redox status of organisms. Accepting the challenge to differentiate structurally similar cysteine (Cys) and homocysteine (Hcy), we have successfully developed a miniature synthetic turn-on fluorescent probe based on 6-(2-benzothiazolyl)-2naphthalenol for Cys. This probe is able to specifically react with Cys to yield its naphthalenol derivative, accompanied by remarkable green fluorescence enhancement with a detection limit of $14.8 \mathrm{nM}$. Besides, this probe displays much greater selectivity for Cys over other biological thiols, including homocysteine (Hcy) and glutathione (GSH). Practically, good cell permeability and low cytotoxicity make it suitable for monitoring basal Cys in living cells.

Received 11th July 2018

Accepted 19th October 2018

DOI: $10.1039 / \mathrm{c} 8 \mathrm{ra05908j}$

rsc.li/rsc-advances

reaction ${ }^{40-42}$ and other mechanisms. ${ }^{43,44}$ To achieve better selectivity of Cys over Hcy and GSH, the Michael addition reaction is among the most widely used strategies for fluorescent sensing of Cys. Strongin and co-workers creatively developed a combination of Michael addition and cyclization reaction to improve the selectivity of Cys/Hcy over GSH. ${ }^{45}$ Yoon and co-workers reported a fluorescent probe based on fluorescein with excellent selectivity and sensitivity for thiols, and it was successfully applied for bio imaging. ${ }^{46}$ Sun and co-workers reported a novel fluorescent probe based on a,bunsaturatedacyl sulfonamide to detect thiols. It reacted selectively with cysteine but not with the other natural amino acids, and subsequently applied to detect intracellular thiols. ${ }^{47}$ Though these probes employ high sensitivity toward thiolcontaining compounds, the selective detection of Cys is still challenging because of disturbance of other biological thiols, especially Hcy. This challenge arises from the structural and reactive similarity between Cys and Hcy which differ by a single methylene of their side chains. Currently claimed fluorescent probes for Cys over Hcy often utilize the different relative kinetical rates which may still cause interference from Hcy after a certain reaction time. Optimal solutions without any kinetical control are in great demand.

As our continuous interests in monitoring cellular redox status changes, ${ }^{4-51}$ we designed and synthesized a simple fluorescent probe 1 to detect cellular Cys in living cells. As demonstrated in Scheme 1, probe 1 carrying an acrylates group, which acts as a Michael addition acceptor is able to react with Cys through thioether formation and followed by cyclization to release emissive fluorophore. Probe 1 is easily accessible by twostep synthesis method, which is weakly-fluorescent with an absolute quantum yield of 0.08 due to the photo induced electron transfer (PET) process. After the reaction with Cys, the

Key Laboratory of Cluster Science of Ministry of Education, Beijing Key Laboratory of Photo-electronic/Electro-photonic Conversion Materials, School of Chemistry and Chemical Engineering, Beijing Institute of Technology, Beijing 100081, P. R. China. E-mail: zhangxl@bit.edu.cn; hellojane@bit.edu.cn; swzhang@bit.edu.cn

$\dagger$ Electronic supplementary information (ESI) available. See DOI: 10.1039/c8ra05908j 

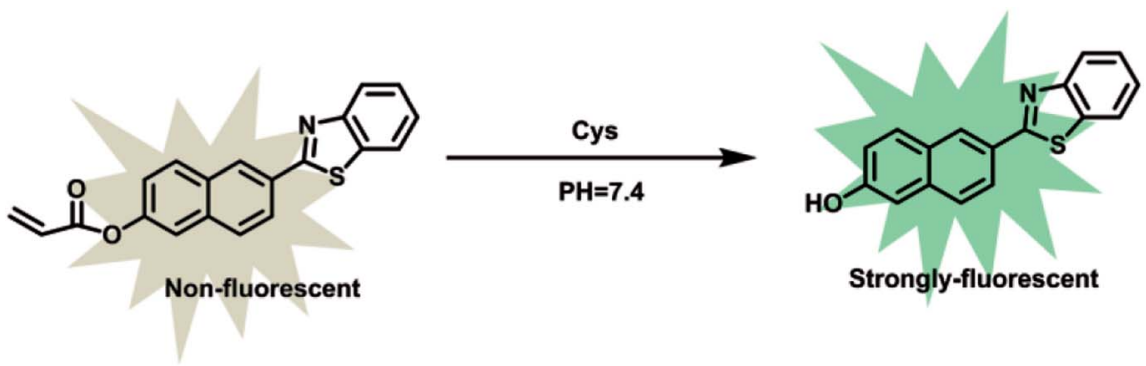

Scheme 1 The reaction mechanism of probe 1 with Cys.

product emits strong green fluorescence and gives an absolute quantum yield of 0.78. Experimental results show that probe 1 exhibits high sensitivity (the detection limit of $14.8 \mathrm{nM}$ ) against Cys, and high selectivity over Hcy and other biological thiols. More importantly, probe 1 showed good cell permeability, low cytotoxicity and was successfully applied to imaging basal Cys in living cells.

\section{Experimental}

\subsection{Materials and instrumentals}

All other chemicals used in this paper were obtained from commercial suppliers and used without further purification. Silica gel (200-300 mesh, Qingdao Haiyang Chemical Co.) was used for column chromatography. NMR spectra were recorded on a Bruker Avance III at $400 \mathrm{MHz}$ for ${ }^{1} \mathrm{H}$ NMR and at $100 \mathrm{MHz}$ for ${ }^{13} \mathrm{C}$ NMR with chemical shifts reported as ppm (in DMSO- $d_{6}$ TMS as internal standard). Mass spectra (MS) were measured with Bruker Apex IV FTMS using electrospray ionization (ESI). Absorption spectra were recorded on a Purkinje TU-1901 spectrophotometer. Fluorescence measurements were taken on a Hitachi F-7000 fluorescence spectrometer with a $10 \mathrm{~mm}$ quartz cuvette. $\mathrm{pH}$ measurements were carried out with a $\mathrm{pH}$ acidometer (Mettler Toledo FE-30). Fluorescence imaging was observed under an Olympus IX81 confocal fluorescence microscope. The absolute fluorescence quantum yield values were measured using Hamamatsu Photonic Multi-Channel Analyzer PMA-12.

\subsection{General procedure for analysis}

Parent stock solution of fluorescent probe $1(1.0 \mathrm{mM})$ was prepared in dimethyl sulfoxide (DMSO). The solution of test was prepared by placing $50 \mu \mathrm{L}$ of parent stock solution and appropriate volume of other solution into the test tube, then diluting the solution to $10 \mathrm{~mL}$ with the mixture of ethanol and ultrapure water $(2: 8, \mathrm{v} / \mathrm{v})$ containing phosphate buffered saline (PBS, $10 \mathrm{mM}, \mathrm{pH}=7.4$ ). All spectra were obtained in a quartz cuvette (path length $=1 \mathrm{~cm}$ ).

All the solutions $(10.0 \mathrm{mM})$ were prepared in deionized water. All the amino acids were purchased from Sigma-Aldrich Chemical. PBS solution was prepared with $\mathrm{Na}_{2} \mathrm{HPO}_{4}$ and $\mathrm{KH}_{2} \mathrm{PO}_{4}$, and adjusted to $\mathrm{pH}$ 7.4.

\subsection{Determination of the detection limit}

Referring to previous papers, the detection limit was calculated based on fluorescence titration. ${ }^{52}$ Fluorescence titration was carried out in $\mathrm{H}_{2} \mathrm{O}$ /ethanol solution $\left(\mathrm{H}_{2} \mathrm{O}\right.$ : ethanol $=8: 2,(\mathrm{v} / \mathrm{v})$, $10 \mathrm{mM}$ PBS, $\mathrm{pH}=7.4$ ) to determine the detection limit, which was then calculated with the following equation:

$$
\text { Detection limit }=3 \sigma / k
$$

Where $\sigma$ is the standard deviation of blank measurements, $k$ is the slope between the fluorescence intensity vs. Cys concentration.

\subsection{Cytotoxicity assay}

HeLa cells were cultured in culture media (DMEM) in an atmosphere of $5 \% \mathrm{CO}_{2}$ and $95 \%$ air at $37^{\circ} \mathrm{C}$. The cells were seeded into 96-well plates at a density of $3 \times 10^{3}$ cells per well in culture media, then $0,5,10 \mu \mathrm{M}$ probe 1 were added, respectively. Next, the cells were incubated at $37^{\circ} \mathrm{C}$ in an atmosphere of $5 \% \mathrm{CO}_{2}$ and $95 \%$ air for $24 \mathrm{~h}$. Finally, $20 \mu \mathrm{L}$ MTT was added and cultured for another $4 \mathrm{~h}$, respectively.

\subsection{Cell culture and imaging}

HeLa cells were grown on glass-bottom culture dishes using DMEM supplemented with $10 \%(\mathrm{v} / \mathrm{v})$ fetal bovine serum (FBS) and $50 \mu \mathrm{g} \mathrm{mL} \mathrm{L}^{-1}$ penicillin-streptomycin in a humidified $37^{\circ} \mathrm{C}$,

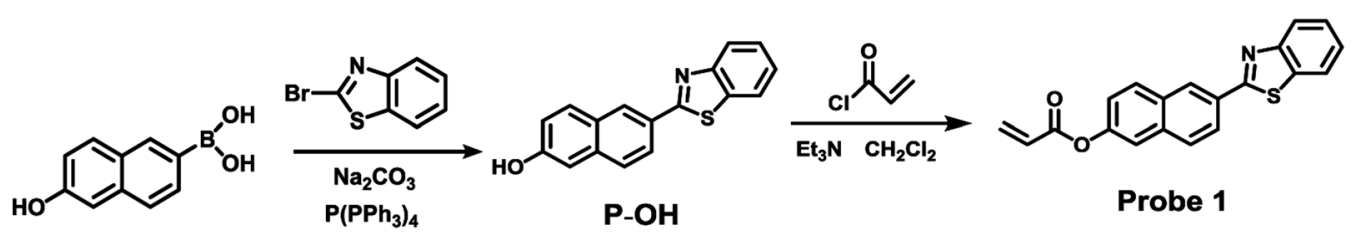

Scheme 2 Synthesis of probe 1. 

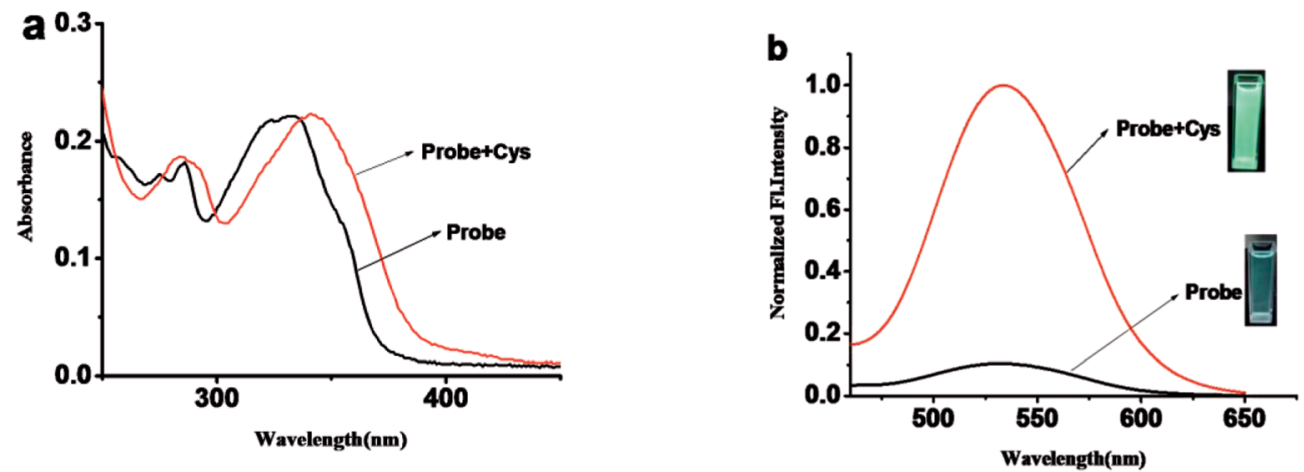

Fig. 1 (a) Absorption spectra of probe $1(5 \mu \mathrm{M})$ in the absence and presence of Cys $(60 \mu \mathrm{M})$ in $\mathrm{H}_{2} \mathrm{O}$ : ethanol $=8: 2(\mathrm{v} / \mathrm{v}), \mathrm{pH}=7.4,10 \mathrm{mM}$ PBS. (b) Fluorescence spectra of probe $1(5 \mu \mathrm{M})$ in the absence and presence of Cys $(60 \mu \mathrm{M})$ in $\mathrm{H}_{2} \mathrm{O}$ : ethanol $=8: 2(\mathrm{v} / \mathrm{v}), \mathrm{pH}=7.4,10 \mathrm{mM}$ PBS. Excitation wavelength is $400 \mathrm{~nm}$, excitation and emission slit widths are $5 \mathrm{~nm}$ and $5 \mathrm{~nm}$. Each spectrum was acquired 40 min after Cys-addition at room temperature.

$5 \% \mathrm{CO}_{2}$ incubator. Before use, the adherent cells were washed three times with FBS-free DMEM. The cells were incubated with $5 \mu \mathrm{M}$ probe in culture media for $30 \mathrm{~min}$ at $37{ }^{\circ} \mathrm{C}$ and then washed with PBS (pH 7.4) twice. Fluorescence imaging of HeLa cells was observed under an Olympus IX81 confocal fluorescence microscope, and the excitation wavelength was $405 \mathrm{~nm}$.

\subsection{Synthesis of fluorescent probe 1}

2.6.1 Synthesis of P-OH. The synthesis route of probe 1 was shown in Scheme 2. (6-Hydroxynaphthalen-2-yl)boronic acid (1 eq.), 2-bromobenzo[d]thiazole(1 eq.),sodium carbonate (3 eq.) and tetrakis(triphenylphosphine)palladium $(0.05$ eq.) were added to a $21 \mathrm{~mL}$ solution $\left(V_{\text {Methanol }}: V_{\text {Toluene }}: V_{\mathrm{H}_{2} \mathrm{O}}=1: 1: 1\right)$. The mixture was refluxed for $3 \mathrm{~h}$ then cooled to ambient temperature. Poured into the water, the solution was adjusted by acid and stand for $10 \mathrm{~min}$, and the precipitate was obtained by filtration. The filtrate was evaporated under reduced pressure and purified by silica gel column chromatography affording $\mathbf{P}$ OH as white solid. 1H NMR (400 MHz, DMSO) $\delta 10.14(\mathrm{~s}, 1 \mathrm{H})$, $8.56(\mathrm{~s}, 1 \mathrm{H}), 8.16(\mathrm{~d}, J=7.9 \mathrm{~Hz}, 1 \mathrm{H}), 8.12-7.99(\mathrm{~m}, 2 \mathrm{H}), 7.86(\mathrm{~d}, J$ $=8.6 \mathrm{~Hz}, 1 \mathrm{H}), 7.56(\mathrm{t}, J=7.6 \mathrm{~Hz}, 1 \mathrm{H}), 7.46(\mathrm{t}, J=7.5 \mathrm{~Hz}, 1 \mathrm{H})$, $7.20(\mathrm{~d}, J=13.6 \mathrm{~Hz}, 1 \mathrm{H})$.
2.6.2 Synthesis of fluorescent probe 1 . To a solution of $\mathbf{P}$ OH (1 eq.) and $\mathrm{Et}_{3} \mathrm{~N}$ (4 eq.) in $10 \mathrm{~mL}$ of anhydrous $\mathrm{CH}_{2} \mathrm{Cl}_{2}$, acryloyl chloride (3 eq.) was added dropwise in an ice-bath. After stirring at $0{ }^{\circ} \mathrm{C}$ for $1 \mathrm{~h}$, the mixture was warmed to room temperature and stirred for another $16 \mathrm{~h}$. The resulting solution was diluted with $\mathrm{CH}_{2} \mathrm{Cl}_{2}(30 \mathrm{~mL})$ and washed with $\mathrm{H}_{2} \mathrm{O}(3 \times 15$ $\mathrm{mL}$ ) and dried over anhydrous $\mathrm{Na}_{2} \mathrm{SO}_{4}$. Solvent was removed by rotavapor. Purification by silica gel column chromatography afforded probe 1 as yellow solid. ${ }^{1} \mathrm{H}$ NMR $(400 \mathrm{MHz}, \mathrm{DMSO})$ $\delta 8.76(\mathrm{~s}, 1 \mathrm{H}), 8.31-8.23(\mathrm{~m}, 2 \mathrm{H}), 8.20(\mathrm{~d}, J=8.0 \mathrm{~Hz}, 1 \mathrm{H}), 8.11(\mathrm{~d}$, $J=8.4 \mathrm{~Hz}, 2 \mathrm{H}), 7.87(\mathrm{~s}, 1 \mathrm{H}), 7.59(\mathrm{t}, J=7.5 \mathrm{~Hz}, 1 \mathrm{H}), 7.50(\mathrm{t}, J=$ $7.5 \mathrm{~Hz}, 2 \mathrm{H}), 6.62(\mathrm{~d}, J=17.2 \mathrm{~Hz}, 1 \mathrm{H}), 6.50(\mathrm{dd}, J=17.2,10.2 \mathrm{~Hz}$, $1 \mathrm{H}), 6.22(\mathrm{~d}, J=10.1 \mathrm{~Hz}, 1 \mathrm{H}) \cdot{ }^{13} \mathrm{C}$ NMR $(700 \mathrm{MHz}, \mathrm{DMSO})$ $\delta 167.63,164.70,154.10,149.80,135.17,135.07,134.51,131.37$, 131.10, 130.74, 129.25, 128.05, 127.73, 127.26, 126.16, 125.21, 123.39, 123.22, 122.93, 119.26. ESI-HRMS calcd for $\mathrm{C}_{20} \mathrm{H}_{13} \mathrm{NO}_{2} \mathrm{~S}$ $[\mathrm{M}+\mathrm{H}]^{+}: 332.0740$, found 332.0742 .

\section{Results and discussion}

\subsection{Response of probe 1 to Cys}

The absorption and fluorescence spectra of probe 1 were measured in $\mathrm{H}_{2} \mathrm{O} /$ ethanol solution $(8: 2, \mathrm{v} / \mathrm{v}, 10 \mathrm{mM}$ PBS, $\mathrm{pH}=$
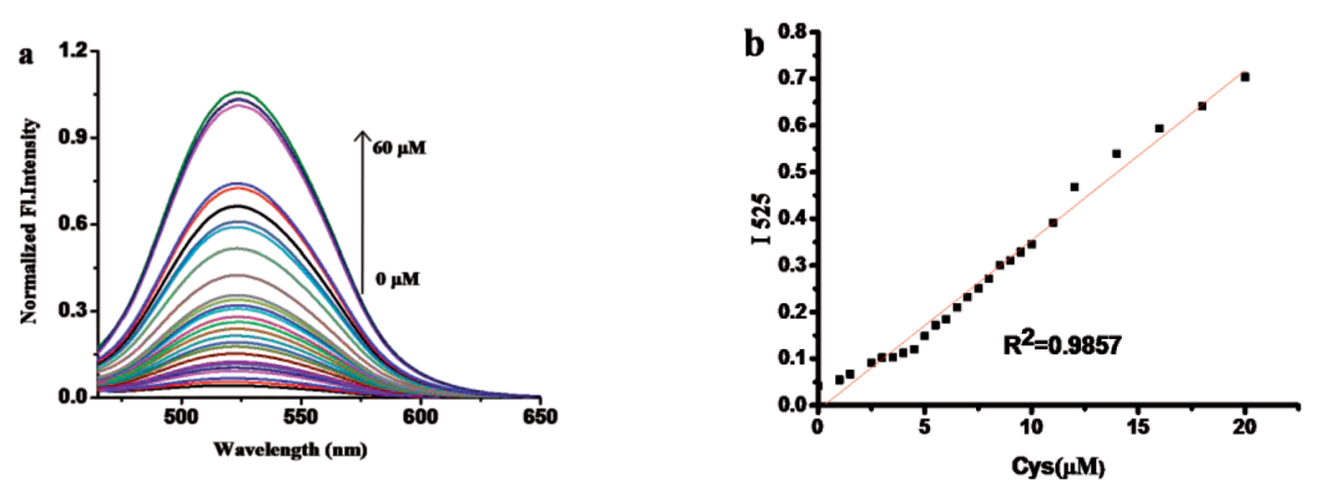

Fig. 2 (a) The fluorescence spectra of probe $1(5 \mu \mathrm{M})$ in the presence of different concentrations of $\mathrm{Cys}$ in $\mathrm{H}_{2} \mathrm{O}:$ ethanol $=8: 2(\mathrm{v} / \mathrm{v}), \mathrm{pH}=7.4$, $10 \mathrm{mM}$ PBS at room temperature. (b) The plot of fluorescence intensity at $525 \mathrm{~nm}$ vs. Cys concentrations. Excitation wavelength is $400 \mathrm{~nm}$, excitation and emission slit widths are $5 \mathrm{~nm}$ and $5 \mathrm{~nm}$. 

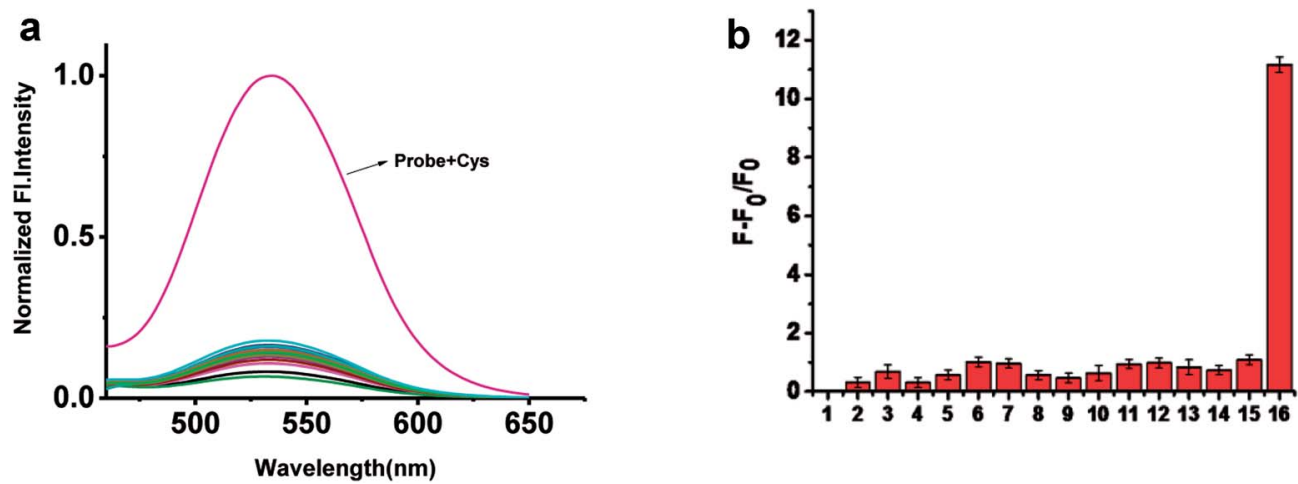

Fig. 3 (a) The fluorescence spectra of probe $1(5 \mu \mathrm{M})$ toward Cys $(10 \mu \mathrm{M}), \mathrm{Hcy}, \mathrm{GSH}$ and various amino acids $(10 \mu \mathrm{M})$ in $\mathrm{H}_{2} \mathrm{O}:$ ethanol $=8: 2(\mathrm{v} / \mathrm{v})$, $\mathrm{pH}=7.4,10 \mathrm{mM}$ PBS at room temperature: the inset shows the fluorescence of various solution under the Handhold UV Lamps (365 nm). (b) Fluorescence intensity changes at 525 nm. (1) Probe 1 (2) L-Leu (3) Ala (4) Trp (5) L-Met (6) Val (7) Thr (8) Tyr (9) D-Met (10) Ser (11) Glu (12) Phe (13) D-Leu (14) GSH (15) Hcy (16) Cys. Excitation wavelength is $400 \mathrm{~nm}$, excitation and emission slit widths are $5 \mathrm{~nm}$ and $5 \mathrm{~nm}$. Each spectrum was acquired $40 \mathrm{~min}$ after various analytes addition at room temperature.

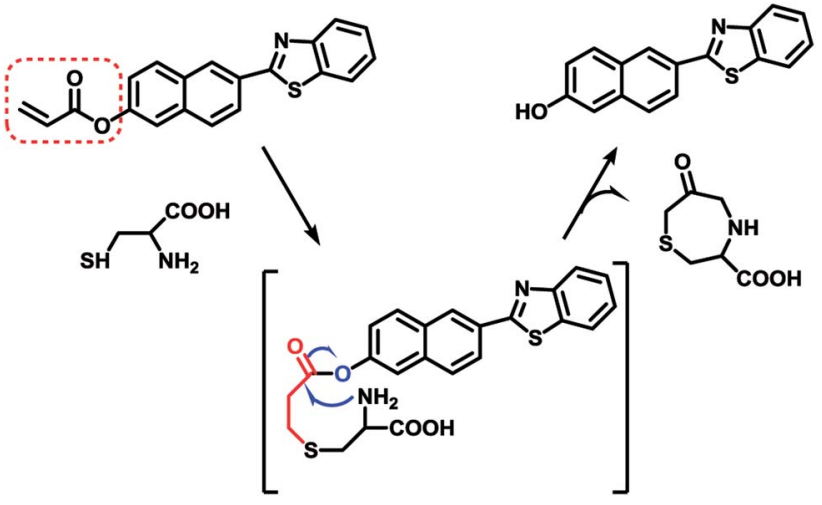

Scheme 3 Proposed response mechanism of probe 1 to Cys.

7.4). As shown in Fig. 1, probe 1 shows a maximum absorption at $331 \mathrm{~nm}$ and weak fluorescence with a relatively low quantum yield of 0.08 . After the addition of Cys, the maximum absorption red shifted $13 \mathrm{~nm}$ to $343 \mathrm{~nm}$ (Fig. 1a). Meanwhile, slight blue

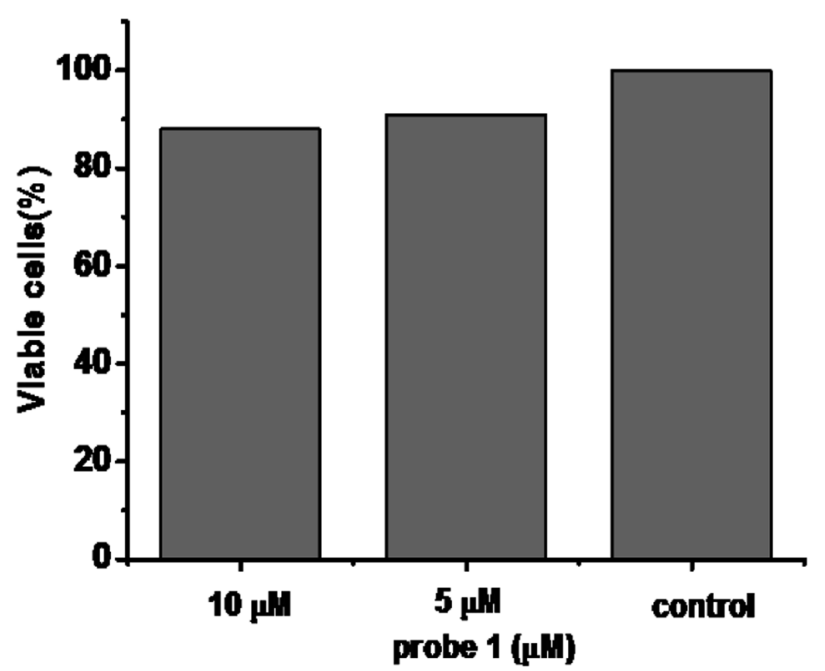

Fig. 4 Cytotoxicity assays of probe 1 at different concentrations for HeLa cells. shift and 24-fold fluorescence enhancement at $525 \mathrm{~nm}$ were obtained and the solution emitted strong green fluorescence under a handhold UV lamp (Fig. 1b), just like we expected, given the absolute quantum yield of 0.78 for the final fluorophore $\mathbf{P}$ OH.

\subsection{Quantification of Cys and detection limit}

The fluorescence spectra of probe 1 with various concentrations of Cys is shown in Fig. 2. Upon gradually increasing of Cys, the fluorescence band centered at $525 \mathrm{~nm}$ increased subsequently. There was a good linearity between the fluorescence intensity at $525 \mathrm{~nm}$ and the concentrations of Cys in the range of 1 to 20 $\mu \mathrm{M}$.The detection limit of Cys is calculated to be $14.8 \mathrm{nM}$. The results show that probe 1 has better detection limit than those reported fluorescent probes for Cys (Table S1†). These above results demonstrated that probe 1 could detect Cys quantitatively by fluorescence spectrometry methods with an excellent sensitivity (Table S1†).

\subsection{The kinetic profile of the recognition of probe 1 for Cys}

The response time of probe 1 towards Cys is evaluated by fluorescence spectroscope. When Cys $(60 \mu \mathrm{M})$ was added to the solution of probe $1(5 \mu \mathrm{M})$, the fluorescence intensity at $525 \mathrm{~nm}$ levels off after $40 \mathrm{~min}$ (Fig. $\mathrm{S} 1 \dagger$ ). The result shows that probe 1 could completely react with Cys within $40 \mathrm{~min}$, thus we chose $40 \mathrm{~min}$ to verify the quantification and selectivity of Cys.

\subsection{The selectivity of probe 1}

To confirm the selectivity of probe 1 towards Cys, other amino acids and GSH were added into the solution of probe 1. As shown in Fig. 3 and S2, $\uparrow$ upon addition of $10 \mathrm{mM} \mathrm{GSH}$, and other amino acids, or cations including $\mathrm{K}^{+}, \mathrm{Na}^{+}, \mathrm{Mg}^{2+}, \mathrm{Al}^{3+}, \mathrm{Fe}^{2+}$ into $5 \mu \mathrm{M}$ probe 1 solution, nearly no fluorescence change were observed except Cys. Only Cys gave12-fold enhancement of fluorescence. 

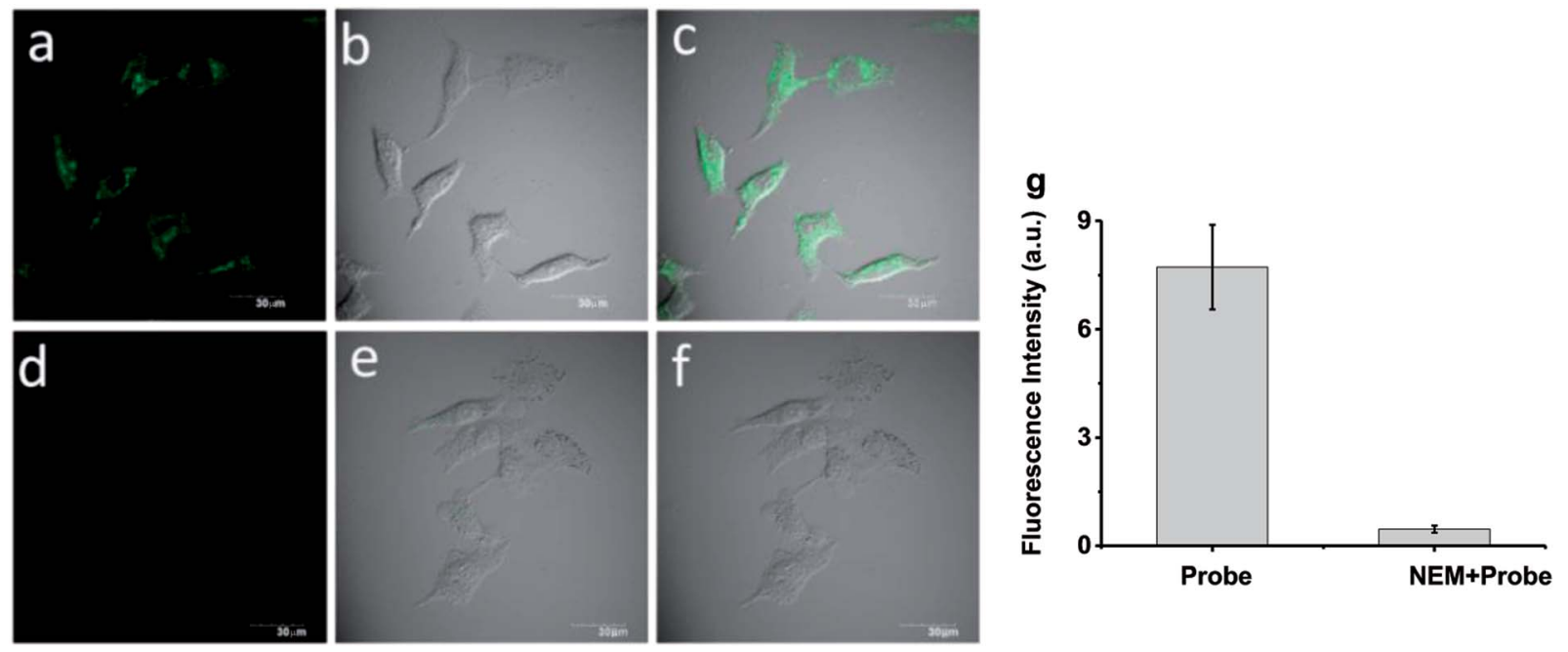

Fig. 5 Fluorescence images of Cys in living cells. (a-c) HeLa cells stained with probe $1(5 \mu M)$ for 30 min. (d-f) HeLa cells were treated with NEM $\left(100 \mathrm{ng} \mathrm{mL}^{-1}\right)$ for $1 \mathrm{~h}$ before incubated with probe $1(5 \mu \mathrm{M})$ for $30 \mathrm{~min}$. (a and d) Fluorescence image. (b and e) Bright field image. (c and f) Merged image. (g) Relative fluorescence intensity of probe 1 treated cells with or without NEM management. Incubation was performed at $37{ }^{\circ} \mathrm{C}$ under a humidified atmosphere containing $5 \% \mathrm{CO}_{2}$. Excitation wavelength is $405 \mathrm{~nm}$, emission wavelength was collected from 450 to $550 \mathrm{~nm}$.

\subsection{Reaction mechanism}

It has been well documented that the acrylate group could be used as an efficient reaction site for Cys. ${ }^{53}$ The mechanism of probe 1 responding to Cys was based on the Michael addition reaction of Cys with the acrylate group to generate the corresponding thioether, a subsequent intramolecular cyclization and further self-immolation to yield the desired lactam, as shown in Scheme 3. To gain further insight into the reaction mechanism, mass spectrometric analysis was carried out to verify the final product after reaction between probe 1 and Cys. ESI-HRMS in Fig. S9† showed a main peak at $m / z 278.0638[\mathrm{M}+$ $\mathrm{H}]^{+}$corresponding to compound $\mathbf{P - O H}$ (calculated at $\mathrm{m} / \mathrm{z}$ 278.0634[M $+\mathrm{H}]^{+}$), which disclosed the proposed mechanism below.

\subsection{Bioimaging applications and cytotoxicity}

To further demonstrate the biological compatibility before real time imaging in living cells,we evaluated the cytotoxicity of probe 1. 3-(4,5-Dimethylthiazol-2-yl)-2,5-diphenyltetrazolium bromide(MTT) assays were performed in HeLa cells with 0, 5, $10 \mu \mathrm{M}$ probe 1 for $24 \mathrm{~h}$, respectively. The viability results in Fig. 4 clearly showed that probe 1 was minimal toxic to cultured cells even at the concentration of as high as $10 \mu \mathrm{M}$. This illustrates probe 1 is suitable for living cell imaging at its work concentration, $5 \mu \mathrm{M}$.

Inspired by the experimental results in vitro of the probe 1 and encouraged by the good biocompatibility, we expected that the high sensitive probe could have a good application for imaging endogenous Cys in living cells. In order to verify our conjecture, HeLa cells were incubated with probe $1(5 \mu \mathrm{M})$ for $30 \mathrm{~min}$, and a strong green fluorescence was observed as shown in Fig. 5a-c. When HeLa cells were treated with $\mathrm{N}$-ethylmaleimide (100 $\mathrm{ng} \mathrm{mL}^{-1}$ )as Cys scavenger for $1 \mathrm{~h}$ before they were incubated with probe $1(5 \mu \mathrm{M})$, hardly any intracellular fluorescence was observed inFig. 5d-f. From Fig. 5g, these results clearly demonstrated that probe 1was cell-permeable and could provide a good option for imaging basal Cys in living cells. Moreover, the same experiments were also tested in normal cells apart from cancer cells, like RAW 264.7 and HepG2 and similar cellular fluorescence change was observed (Fig. S3 and $\mathrm{S} 4 \dagger$ ).

\section{Conclusion}

In summary, we have developed a reaction based turn-on fluorescent probe 1 conjugating with a reactive acrylate for visualization basal Cys in living cells. The synthesis of probe $\mathbf{1}$ is simple, and the probe showed excellent selectivity toward Cys over Hcy. Different from previously reported Cys detection methods, the reactivity between Cys and Hys is significantly different, therefore kinetically disfavorability of Hcy is no longer needed to improve the selectivity. Furthermore, monitoring basal Cys effectively in living cells was easily implemented attributing to its low cytotoxic, good sensitivity and good selectivity towards Cys over Hcy and GSH. This method could became an potential tool to reveal the behaviors of Cys in living organism.

\section{Conflicts of interest}

There are no conflicts to declare.

\section{Acknowledgements}

This work was supported by the National Nature Science Foundation of China (No. 21575015 and 21505004). 


\section{References}

1 Y. Zhou and J. Yoon, Recent progress in fluorescent and colorimetric chemosensors for detection of amino acids, Chem. Soc. Rev., 2012, 41(1), 52-67.

2 J. Yoon, L. Cui, Y. Baek, et al., AIE and ESIPT based kinetic resolved fluorescent probe for Biothiols, J. Mater. Chem. C, 2016, 4(14), 2909-2914.

3 H. S. Jung, J. H. Han, T. Pradhan, et al., A cysteine-selective fluorescent probe for the cellular detection of cysteine, Biomaterials, 2012, 33(3), 945-953.

4 Y. Liu, X. Lv, M. Hou, et al., Selective fluorescence detection of cysteine over homocysteine and glutathione based on a cysteine-triggered dual Michael Addition/Retro-aza-aldol cascade reaction, Anal. Chem., 2015, 87(22), 11475-11483.

5 Y. Kim, S. V. Mulay, M. Choi, et al., Exceptional time response, stability and selectivity in doubly-activated phenyl selenium-based glutathione-selective platform, Chem. Sci., 2015, 6(10), 5435-5439.

6 Y. Yue, F. Huo, P. Ning, et al., Dual-site fluorescent probe for visualizing the metabolism of Cys in living cells, J. Am. Chem. Soc., 2017, 139(8), 3181-3185.

7 H. S. Jung, J. H. Han, T. Pradhan, et al., A cysteine-selective fluorescent probe for the cellular detection of cysteine, Biomaterials, 2012, 33(3), 945-953.

8 H. S. Jung, T. Pradhan, J. H. Han, et al., Molecular modulated cysteine-selective fluorescent probe, Biomaterials, 2012, 33(33), 8495-8502.

9 L. M. Lópezsánchez, C. Lópezpedrera and A. Rodríguezariza, Proteomic approaches to evaluate protein S-nitrosylation in disease, Mass Spectrom. Rev., 2014, 33(1), 7-20.

10 R. Janáky, V. Varga, A. Hermann, et al., Mechanisms of Lcysteine neurotoxicity, Neurochem. Res., 2000, 25(9-10), 1397-1405.

11 S. Shahrokhian, Lead phthalocyanine as a selective carrier for preparation of a cysteine-selective electrode, Anal. Chem., 2001, 73(24), 5972-5978.

12 J. Liu, Y. Q. Sun, Y. Huo, et al., Simultaneous fluorescence sensing of Cys and GSH from different emission channels, J. Am. Chem. Soc., 2014, 136(2), 574-577.

13 W. Hao, A. Mcbride, S. Mcbride, et al., Colorimetric and near-infrared fluorescence turn-on molecular probe for direct and highly selective detection of cysteine in human plasma, J. Mater. Chem., 2011, 21(4), 1040-1048.

14 Y. W. Wang, S. B. Liu, W. J. Ling, et al., A fluorescent probe for relay recognition of homocysteine and Group IIIA ions including Ga(III), Chem. Commun., 2016, 52(4), 827-830.

15 J. Dorszewska, M. Prendecki, A. Oczkowska, et al., Molecular basis of familial and sporadic Alzheimer's disease, Curr. Alzheimer Res., 2016, 13(9), 952-963.

16 D. W. Jacobsen, Acquired hyperhomocysteinemia in heart transplant recipients, Clin. Chem., 1998, 44(11), 2238-2239.

17 S. Seshadri, A. Beiser, J. Selhub, P. F. Jacques, I. H. Rosenberg, R. B. D'Agostino, P. W. Wilson and P. A. Wolf, Plasma homocysteine as a risk factor for dementia and Alzheimer's disease, N. Engl. J. Med., 2002, 346(7), 476-483.

18 X. Li, X. Gao, W. Shi, et al., Design strategies for watersoluble small molecular chromogenic and fluorogenic probes, Chem. Rev., 2014, 114(1), 590-659.

19 J. F. Zhang, Y. Zhou, J. Yoon, et al., ChemInform Abstract: Recent Progress in Fluorescent and Calorimetric Chemosensors for Detection of Precious Metal Ions (Silver, Gold and Platinum Ions), J. Cheminf., 2011, 42(42), 34163429.

20 X. Chen, X. Tian, I. Shin, et al., ChemInform Abstract: Fluorescent and Luminescent Probes for Detection of Reactive Oxygen and Nitrogen Species, Chem. Soc. Rev., 2011, 40(9), 4783-4804.

$21 \mathrm{~J}$. Lu, Y. Song, W. Shi, et al., A long-wavelength fluorescent probe for imaging reduced glutathione in live cells, Sens. Actuators, B, 2012, 161(1), 615-620.

22 H. Maeda, H. Matsuno, M. Ushida, et al., 2,4Dinitrobenzenesulfonyl fluoresceins as fluorescent alternatives to Ellman's reagent in thiol-quantification enzyme assays, Angew. Chem., Int. Ed., 2005, 44(19), 29222925.

23 C. Yin, F. Huo, J. Zhang, et al., ChemInform Abstract: Thiol-Addition reactions and rheirapplications in thiol recognition, Chem. Soc. Rev., 2013, 42(14), 6032-6059.

24 D. Kand, A. M. Kalle, S. J. Varma, et al., A chromenoquinoline-based fluorescent off-on thiol probe for bioimaging, Chem. Commun., 2012, 48(21), 2722-2724.

25 H. S. Jung, T. Pradhan, J. H. Han, et al., Molecular modulated cysteine-selective fluorescent probe, Biomaterials, 2012, 33(33), 8495-8502.

26 B. K. Mcmahon and T. Gunnlaugsson, Selective detection of the reduced form of glutathione (GSH) over the oxidized (GSSG) form using a combination of glutathione reductase and a $\mathrm{Tb}(\mathrm{III})$-cyclen maleimide based lanthanide luminescent 'switch on' assay, J. Am. Chem. Soc., 2012, 134(26), 10725-10728.

27 P. Wang, J. Liu, X. Lv, et al., A naphthalimide-based glyoxal hydrazone for selective fluorescence turn-on sensing of Cys and Hcy, Org. Lett., 2012, 14(2), 520-523.

28 F. Kong, R. Liu, R. Chu, et al., A highly sensitive near-infrared fluorescent probe for cysteine and homocysteine in living cells, Chem. Commun., 2013, 49(80), 9176-9178.

29 X. Zhou, D. Guo, Y. Jiang, et al., A novel AIEE and EISPT fluorescent probe for selective detection of cysteine[J], Tetrahedron Lett., 2017, 58(33), 3214-3218.

30 Y. Lin, W. Lin, Z. Sheng, et al., A unique approach to development of near-infrared fluorescent sensors for in vivo imaging, J. Am. Chem. Soc., 2012, 134(32), 13510-13523.

31 M. Wei, P. Yin, Y. Shen, et al., A new turn-on fluorescent probe for selective detection of glutathione and cysteine in living cells, Chem. Commun., 2013, 49(41), 4640-4642.

32 J. Yin, Y. Kwon, D. Kim, et al., A Cyanine Based Fluorescence Probe for Highly Selective Detection of Glutathione in Cell Cultures and Live Mice Tissues, J. Am. Chem. Soc., 2014, 136(14), 5351-5358. 
33 M. Li, X. Wu, Y. Wang, et al., A near-infrared colorimetric fluorescent chemodosimeter for the detection of glutathione in living cells, Chem. Commun., 2014, 50(14), 1751-1753.

34 L. Y. Niu, Y. S. Guan, Y. Z. Chen, et al., BODIPY-based ratiometric fluorescent sensor for highly selective detection of glutathione over cysteine and homocysteine, J. Am. Chem. Soc., 2012, 134(46), 18928-18931.

35 X. F. Yang, Q. Huang, Y. Zhong, et al., A dual emission fluorescent probe enables simultaneous detection of glutathione and cysteine/homocysteine, Chem. Sci., 2014, 5(6), 2177-2183.

36 S. Y. Lim, K. H. Hong, D. I. Kim, et al., Tunable Heptamethine-Azo dye conjugate as an NIR fluorescent probe for the selective detection of mitochondrial glutathione over cysteine and homocysteine, J. Am. Chem. Soc., 2014, 136(19), 7018-7025.

37 Y. S. Guan, L. Y. Niu, Y. Z. Chen, et al., A near-infrared fluorescent sensor for selective detection of cysteine and its application in live cell imaging, $R S C A d v ., 2014,4(16)$, 8360.

38 H. Lv, X. F. Yang, Y. Zhong, et al., Native chemical ligation combined with spirocyclization of benzopyrylium dyes for the ratiometric and selective fluorescence detection of cysteine and homocysteine, Anal. Chem., 2014, 86(3), 18001807.

39 J. Liu, Y.-Q. Sun, H. Zhang, Y. Huo, Y. Shi and W. Guo, Simultaneous fluorescent imaging of Cys/Hcy and GSH from different emission channels, Chem. Sci., 2014, 5, 3183-3188.

40 J. H. Lee, C. S. Lim, Y. S. Tian, et al., A two-photon fluorescent probe for thiols in live cells and tissues, J. Am. Chem. Soc., 2010, 132(4), 1216-1217.

41 C. S. Lim, G. Masanta, H. J. Kim, et al., Ratiometric detection of mitochondrial thiols with a two-photon fluorescent probe, J. Am. Chem. Soc., 2011, 133(29), 11132-11135.

42 M. H. Lee, J. H. Han, P. S. Kwon, et al., Hepatocyte-targeting single galactose-appended naphthalimide: a tool for intracellular thiol imaging in vivo, J. Am. Chem. Soc., 2012, 134(2), 1316-1322.
43 H. S. Jung, Ji H. Han and Y. Habata, An iminocoumarin$\mathrm{Cu}(\mathrm{II})$ ensemble-based chemodosimeter toward thiols, Chem. Commun., 2011, 47(18), 5142-5144.

44 Y. Bao, Q. Li, B. Liu, et al., Conjugated polymers containing a 2,2'-biimidazole moiety-a novel fluorescent sensing platform, Chem. Commun., 2012, 48(1), 118-120.

45 X. Yang, Y. Guo and R. M. Strongin, Conjugate Addition/ Cyclization sequence enables selective and simultaneous fluorescence detection of cysteine and homocysteine, Angew. Chem., Int. Ed., 2011, 50(45), 10690-10693.

46 X. Chen, S. K. Ko, M. J. Kim, et al., A thiol-specific fluorescent probe and its application for bioimaging, Chem. Commun., 2010, 46(16), 2751.

47 H. Zhang, P. Wang, Y. Yang, et al., A selective fluorescent probe for thiols based on $\alpha, \beta$-unsaturated acyl sulfonamide, Chem. Commun., 2012, 48(86), 10672-10674.

48 C. Gao, Y. Tian, R. B. Zhang, et al., Endoplasmic reticulum directed ratiometric fluorescent probe for quantitively detection of basal $\mathrm{H}_{2} \mathrm{O}_{2}$, Anal. Chem., 2017, 89(23), 1294512950.

49 B. Guo, H. Nie, W. Yang, et al., A highly sensitive and rapidly responding fluorescent probe with a large Stokes shift for imaging intracellular hypochlorite, Sens. Actuators, B, 2016, 236, 459-465.

50 B. Guo, J. Jing, H. Nie, et al., A lysosome-targetable versatile fluorescent probe for imaging viscosity and peroxynitrite with different fluorescence signals in living cells, J. Mater. Chem. B, 2018, 6, 580-585.

51 Y. Tian, F. Xin, C. Gao, et al., Ratiometric fluorescent imaging for endogenous selenocysteine in cancer cell matrix, J. Mater. Chem. B., 2017, 5, 6890-6896.

52 C. Liu, C. Shao, H. Wu, et al., A fast-response, highly sensitive and selective fluorescent probe for the ratiometric imaging of hydrogen peroxide with a $100 \mathrm{~nm}$ red-shifted emission, RSC Adv., 2014, 4(31), 16055-16061.

53 N. J. Leonard and R. Y. Ning, The synthesis and stereochemistry of substituted 1,4-thiazepines related to the penicillins, J. Org. Chem., 1966, 31(12), 3928-3935. 